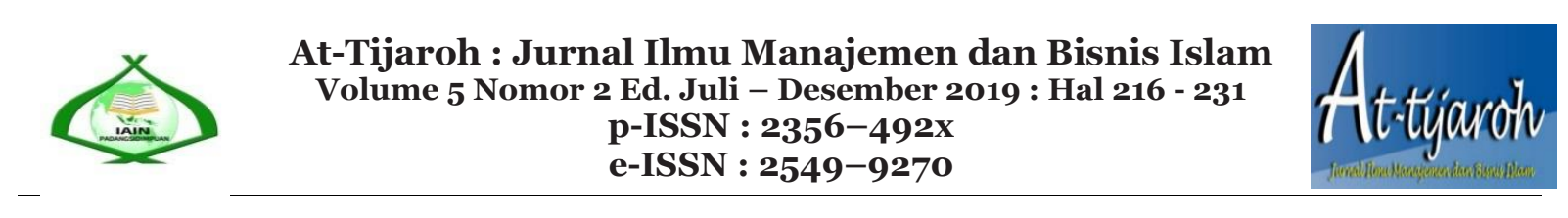

\title{
KESADARAN KONSUMEN MENGGUNAKAN KOSMETIK HALAL SERTA PENGARUHNYA TERHADAP BRAND HOLISTIC
}

\author{
Sri Wahyuni Hasibuan¹, M. Yasir Nasution² Saparuddin Siregar3 \\ Universitas Islam Negeri Sumatera Utara \\ Jl. Willem Iskandar Pasar V Medan Estate, Sumatera Utara \\ 1yuni.hsb@gmail.com
}

\begin{abstract}
Indonesia as a supplier of halal cosmetics is inferior to other halal cosmetics providers. This is due to the disintegration of functional, emotional, and spiritual aspects of cosmetics, which can result in low consumer awareness. This research is an explanatory research using variance-based SEM approach. The results showed that consumer awareness of using halal cosmetics is due to knowledge, beliefs, experience, and information about cosmetics. Consumer awareness of using halal cosmetics has a positive and significant effect on brand holism. This awareness is due to the integration of the brand holistic elements in cosmetics, namely (1) it does not conflict with the principle of trust; (2) beautiful and healthy; (3) using natural ingredients; (4) care for the environment and reject exploitation; (5) free of animal fat; (6) clean manufacturing process; (7) strict supervision of label / logo certification; (8) does not cause dependency; (9) provide peace of mind, body and soul; (10) exposure according to reality; (11) and can be used various human backgrounds. So it is recommended for cosmetics companies to be able to strengthen their brands and be able to compete in the global market, it is very important to integrate all these elements in their brands.
\end{abstract}

Keywords: Awareness, Halal Cosmetics, Brand Holistic

\begin{abstract}
Abstrak
Indonesia sebagai pemasok kosmetik halal kalah dengan negara penyedia kosmetik halal lainnya. Hal ini disebabkan terjadinya disintegrasi antara aspek fungsional, emosional, dan spiritual pada kosmetik, yang dapat mengakibatkan rendahnya kesadaran konsumen.. Penelitian ini termasuk explanatory research dengan menggunakan penedekatan SEM berbasis variance. Hasil penelitian menunjukkan bahwa kesadaran konsumen menggunakan kosmetik halal disebabkan karena pengetahuan, keyakinan, pengalaman, dan informasi tentang kosmetik tersebut. Kesadaran konsumen menggunakan kosmetik halal berpengaruh positif dan signifikan terhadap brand holistic. Kesadaran ini disebabkan terintegrasinya unsur-unsur brand holistic pada kosmetik tersebut, yaitu (1) tidak bertentangan dengan prinsip kepercayaan; (2) indah dan sehat; (3) menggunakan bahan-bahan alami; (4) peduli lingkungan dan menolak eksploitasi; (5) bebas dari lemak hewani; (6) proses pembuatan yang bersih; (7) pengawasan yang ketat terhadap sertifikasi label/logo; (8) tidak menyebabkan ketergantungan; (9) memberikan ketenangan akal pikiran, jiwa dan raga; (10) pemaparan yang sesuai dengan kenyataan; (11) dan dapat digunakan berbagai latar belakang manusia. Maka disarankan bagi perusahaan kosmetik agar dapat memperkokoh brandnya dan dapat bersaing pada pasar global, sangat penting mengintegrasikan semua unsur ini pada mereknya.
\end{abstract}

Kata Kunci: Kesadaran, Kosmetik Halal, Brand Holistic 


\section{7 |Kesadaran Konsumen Menggunakan Kosmetik Halal Serta Pengaruhnya Terhadap Brand Holistic}

\section{PENDAHULUAN}

Konsumsi tidak hanya semata-mata makan dan minum, tetapi mencakup segala pemakaian dan pemanfaatan barang dan jasa untuk memenuhi kebutuhan manusia dalam kehidupan sehari-hari (Al-Qordhawi, 1995). Salah satunya adalah pemakaian kosmetika, yang merupakan bahan atau campuran bahan yang digunakan untuk membersihkan, menjaga, meningkatkan penampilan, digunakan dengan cara mengoles, menempel, memercik atau menyemprot (Fatwa MUI No. 26 Tahun 2003). Bedak, lipstik, dan pembersih muka merupakan sebagian dari kosmetik.

Menurut pandangan Qardhawi (1985) wanita boleh berhias dengan ketentuan ada sebagian bentuk dan berhias yang dilarang, yaitu bentuk dan cara berhias yang menyalahi fitrah dan mengubah bagian-bagian tubuh ciptaan Allah. Fatwa MUI (2013) membolehkan penggunaan kosmetika dengan syarat halal dan suci, ditujukan untuk kepentingan yang dibolehkan secara syar'i dan tidak membahayakan. Ar-razi (2003) menafsirkan kata Halalan adalah kebolehan dan terlepas dari unsur yang berbahaya. Sedangkan kata Thoyyiban adalah lezat, baik dan bukan milik orang lain. Sedangkan haram disebabkan karena kotor, tidak baik, seperti bangkai, darah, khamr, dan sesuatu yang dapat merusak. Terkadang haram itu bukan saja karena kotor tetapi milik orang lain. Maksud pendapat tersebut kosmetik yang dibolehkan dalam Syari'at Islam adalah berasal dari bahan-bahan yang baik, diproduksi secara baik seperti higienis, dan bahannya tidak berasal dari hasil ekploitasi seperti menyebabkan kepunahan. Berdasarkan hal tersebut Syariat Islam mewajibkan bagi ummatnya untuk menggunakan kosmetik halal. Sebab tidak hanya sholat mengharuskan seseorang harus suci badan dari najis.

Kosmetik halal itu sendiri saat ini tidak hanya menjadi budaya dan konsumsi penduduk muslim, namun sudah mulai menjadi gaya hidup konsumsi dunia. Dr. Mah Hussain-Gambles, pendiri perusahaan kosmetik halal pertama di Eropa dapat meraih 75\% pelanggan non muslim (Isablle, 2015). Selain itu Laporan State of the Global of Islamic Economic yang dikeluarkan oleh Thompson Reuters dan Dinar Standar, bahwa peluang yang menjanjikan dalam sektor ekonomi untuk produk halal diantaranya produk farmasi dan kosmetik. Produk ini memiliki nilai sebesar US\$ 72 milyar dan diperkirakan di tahun 2019 memperoleh US\$ 103 milyar yaitu sama dengan 6,6\% total penggunaan dunia (Kementerian Perdagangan Republik Indonesia, 2015).

Berdasarkan laporan Thompson, pasar kosmetika muslim berada pada peringkat ke-4 (empat) secara global sedangkan Indonesia sebagai pemasok kosmetik halal berada pada peringkat ke-8. Hal ini menunjukkan bahwa Indonesia kalah dengan Negara penyedia kosmetik halal lainnya seperti Uni Emirat Arab diperingkat pertama, Malaysia diurutan kedua, bahkan Singapura yang berada diurutan ketiga. Harapannya Indonesia dapa meningkat dan 
dapat bersaing karena industri kosmetik halal memiliki peluang yang besar pada pasar global bahkan di Indonesia sendiri potensi pasar kosmetika tinggi.

Tingginya peluang kosmetik halal disebabkan aspek spiritual semakin penting dalam memproduksi kosmetik. Faktor yang memengaruhi konsumen menggunakan kosmetik halal telah sejajar dengan faktor ekonomi, politik dan sosial. Sehingga perusahaan lebih tertarik memproduksi merek yang lebih spesifik, yang dapat juga di konsumsi oleh kelompok etnis tertentu. Konsumen muslim merupakan target pasar yang menjanjikan karena memiliki minat beli yang tinggi terhadap kosmetik.

Melonjaknya peminat produk kosmetik merupakan tantangan bagi produsen kosmetik untuk meningkatkan kualitas produk kosmetiknya agar dapat bersaing dengan merek yang lainnya. Maka agar merek dapat bersaing di pasar nasional maupun internasional penting mempelajari merek dari psikologi konsumen yaitu kesadarannya. Karena merek adalah tulang punggung pemasaran dan perhatian semua departemen perusahaan. Merek adalah ciptaan interdisipliner. Piramida merek ideal menyiratkan manajer yang sukses, membutuhkan masukan dari semua seni dan ilmu yang berkontribusi dan memiliki kemampuan untuk mengintegrasikan mereka kedalam kesatuan yang kohesif dan khas (Levy, 1974). Moore dan Reid (2008) berpendapat bahwa sebagian besar riset yang ada pada merek telah fokus pada perspektif konsumen untuk memproduksi merek yang efektif.

Kesadaran konsumen terhadap kosmetik halal dapat berdampak pada brand holistic, karena aspek spiritual merupakan bagian yang tidak dapat terpisahkan dari merek. Isabelle (2015) berpendapat bahwa kosmetik halal dan țayyīb selaras dengan merek kosmetik menurut pandangan dunia, karena memiliki nilai-nilai universal. Kosmetik halal dapat digunakan berbagai kalangan baik muslim maupun non muslim. Ini menunjukkan bahwa kosmetik halal itu bersifat holism dan dinamis yaitu dapat dipakai oleh seluruh konsumen, berlaku setiap zaman serta memiliki dimensi yang utuh. Berdasarkan latar belakang masalah tersebut yang menjadi tujuan dari penelitian ini adalah untuk mengetahui indikator yang mempengaruhi kesadaran konsumen menggunakan kosmetik halal serta pengaruhnya terhadap brand holistic.

Menurut Pawlik (1998) kesadaran disebabkan oleh pengetahuan dan keyakinan. Zeman (2001) menerangkan kesadaran berasal dari pengalaman. Sedangkan Anderson (1994) menjelaskan bahwa konsumen menaruh kepercayaan mereka pada sumber informasi yang diterima. Berdasarkan beberapa pendapat tersebut kemungkinan konsumen sadar menggunakan kosmetik halal berasal dari pengetahuan, keyakinan, pengalaman, dan informasi yang didapatkan seseorang tentang kosmetik.

Halal dan Thoyyib dapat mempengaruhi kesadaran konsumen menggunakan kosmetik. Isabelle (2015) berpendapat bahwa kosmetik halal dan toyyiban selaras dengan 


\section{9 |Kesadaran Konsumen Menggunakan Kosmetik Halal Serta Pengaruhnya Terhadap Brand Holistic}

merek kosmetik menurut pandangan dunia (brand holistic), yaitu memiliki nilai-nilai universal. Brand adalah label yang menggambarkan jenis dan tingkat barang tertentu (Levy, 1974). Sedangkan holistic berkembang dari teori psikologi yaitu pemikiran dan pandangan duniawi yang tidak dibatasi oleh dogma, iman ilahi tertentu, atau sitem kepercayaan tertentu (Smuts, 1973).

Al-Asyqar (2013) pada saat menafsirkan suroh as-Saba' ayat 28 yaitu kami mengutusmu wahai Nabi melainkan untuk seluruh manusia, bangsa Arab dan bangsa Asing sebagai pemberi kabar gembira. Kaitan ayat ini dengan kosmetik halal, bahwa halal adalah konsep Syari'at Islam yang disampaikan kepada Nabi yang dapat memberi dampak positif untuk seluruh ummat.

Menurut Keller (2001) upaya membangun merek adalah memiliki nilai yang positif dan dapat di akses, menjalin hubungan merek dengan pelanggan yang ditunjukkan dengan kepatuhan yang sungguh-sungguh dan selalu aktif. Aeker (1997) mengidentifikasi lima (5) dimensi kepribadian dan nilai-nilai yang harus ada pada merek yaitu: (1) ketulusan seperti jujur, sehat, rendah hati dan ceria; (2) kegembiraan seperti bersemangat, imajinatif, berani dan terkini; (3) kompetensi, seperti sukses, dapat diandalkan dan cerdas; (4) kecanggihan seperti kelas atas dan menawan; (5) tangguh.

Isabelle dan Tournois (2015) mengidentifikasi empat atribut brand holistic yaitu: (1) system etos dan kepercayaan spiritual; (2) filosofi yang berkelanjutan; (3) kesehatan, dan (4) Inkluvsivitas. Kemungkinan kesadaran konsumen menggunakan kosmetik halal berdasarkan atribut ini. Oleh karena itu penulisan penelitian ini untuk mengetahui kesadaran konsumen menggunakan kosmetik halal serta pengaruhnya terhadap brand holistic.

\section{METODE PENELITIAN}

Penelitian ini digolongkan penelitian explanatory research. Menurut Sugiyono (2012) eksplanatori termasuk penelitian yang menerangkan hubungan antara satu variabel dengan yang lain. Populasi dalam penelitian ini adalah wanita dewasa. Menurut Sudjana (2005) populasi adalah totalitas seluruh nilai yang mungkin, hasil menghitung atau pengukuran, kuantitatif maupun kualitatif mengenai karakteristik tertentu dari semua anggota kumpulan yang lengkap dan jelas yang ingin dipelajari sifat-sifatnya. Sedangkan sampel penelitian adalah sebagian dari populasi yang memiliki sifat dan karakter yang sama sehingga betul-betul mewakili populasinya.

Adapun kualifikasi dari sampel penelitian adalah konsumen yang menggunakan kosmetik berlabel halal dan umur 20-44 tahun. Karena tidak diketahui jumlah populasi yang sesuai dengan kualifikasi tersebut maka pengambilan sampel ditentukan berdasarkan convenience sampling (kuncoro, 2003). Data dikumpulkan melalui media online yaitu whatsApp, facebook dan gmail. Waktu pengumpulan kuesioner ditetapkan satu bulan. 
Kuesioner yang terkumpul yaitu 108 responden. Namun yang diolah adalah 100 kuesioner dikarenakan terdapat beberapa konsumen yang mengisi dua samapi tiga kali. Gambaran umum responden berdasarkan ketegorinya yaitu dapat dilihat pada tabel dibawah ini:

\section{Tabel 1}

Gambaran Umum Responden

\begin{tabular}{|c|c|c|c|}
\hline Karakteristik & Kategori & Frekuensi & Persentase \\
\hline \multirow{5}{*}{ Umur } & 20-24 Tahun & 35 & $35 \%$ \\
\hline & 25-29 Tahun & 20 & $20 \%$ \\
\hline & 30-34 Tahun & 24 & $24 \%$ \\
\hline & 35-39 Tahun & 11 & $11 \%$ \\
\hline & 40-44 Tahun & 10 & $10 \%$ \\
\hline \multirow[t]{4}{*}{ Pendidikan } & Diploma & 7 & $7 \%$ \\
\hline & Sarjana & 75 & $75 \%$ \\
\hline & SMA & 17 & $17 \%$ \\
\hline & SMP & 1 & $1 \%$ \\
\hline \multirow[t]{8}{*}{ Pekerjaan } & Dokter & 1 & $1 \%$ \\
\hline & Dosen & 4 & $4 \%$ \\
\hline & IRT & 7 & $7 \%$ \\
\hline & Mahasiswa & 32 & $32 \%$ \\
\hline & Pegawai Negeri & 20 & $20 \%$ \\
\hline & Pegawai Swasta & 26 & $26 \%$ \\
\hline & Pengangguran & 1 & $1 \%$ \\
\hline & Wiraswasta & 9 & $9 \%$ \\
\hline \multirow{5}{*}{$\begin{array}{l}\text { Merek Kosmetik } \\
\text { Berlabel Halal Yang } \\
\text { Pernah Digunakan }\end{array}$} & Mazaya & 4 & $4 \%$ \\
\hline & SAFI & 1 & $1 \%$ \\
\hline & Wardah & 86 & $86 \%$ \\
\hline & Zoya & 4 & $4 \%$ \\
\hline & Lainnya & 5 & $5 \%$ \\
\hline
\end{tabular}

Tabel 1, menunjukkan sebagian besar responden berada pada usia 20-24 tahun yaitu sebanyak 35\%, kualifikasi pendidikan sebagian besar respondennya adalah sarjana sebanyak 75 responden, kualifikasi pekerjaan sebagian besar respondennya adalah mahasiswa sebanyak $32 \%$, dan kualifikasi merek kosmetik berlabel halal yang pernah digunakan sebagian besar responden menggunkan merek wardah yaitu sebanyak $86 \%$ responden.

Instrumen penelitian yang dipakai sebagai alat ukur variabel kesadaran adalah modifikasi dari pendapat Pawlik (1998), Zeman (2001), dan Anderson (1994) yaitu keyakinan, pengetahuan, pengalaman dan informasi. Sedangkan variabel brand holistic diukur dengan indikator sebagai berikut: (1) system etos dan kepercayaan spiritual; (2) filosofi yang berkelanjutan; (3) kesehatan, dan (4) Inkluvsivitas (Isabelle dan Tournois, 2015).

Untuk mengidentifikasi kecendrungan kesadaran terlebih dahulu dihitung nilai ratarata ideal $=12$ dan Standar deviasi ideal $=2,67$. Berdasarkan hal tersebut diperoleh interval persentase skor untuk setiap kategori adalah sebagai berikut: 


\section{1 |Kesadaran Konsumen Menggunakan Kosmetik Halal Serta Pengaruhnya Terhadap Brand Holistic}

Tabel 2

Klasifikasi Persentase Interval

\begin{tabular}{|c|c|c|}
\hline \multirow{2}{*}{ No } & \multicolumn{2}{|c|}{ Klasifikasi } \\
\cline { 2 - 3 } & Rentang Skor & Kategori \\
\hline 1 & 16,81 keatas & Sangat Tinggi \\
\hline 2 & $13,60-16,81$ & Tinggi \\
\hline 3 & $10,39-13,60$ & Sedang \\
\hline 4 & $7,19-10,39$ & Rendah \\
\hline 5 & $7,19-$ Kebawah & Sangat Rendah \\
\hline
\end{tabular}

Ada 4 pernyataan yang menjadi indikator kesadaran. Pernyataan itu meliputi kesadaran konsumen mengunakan kosmetik halal yaitu mengetahui kosmetik halal adalah produk kecantikan yang sesuai dengan keyakinan agama Islam, menghindari produk kosmetik yang tidak jelas kehalalannya (subhat), menggunakan kosmetik halal dan baik, dan mencari informasi tentang kejelasan kosmetik halal. Hasil tanggapan 100 orang responden terhadap 4 pernyataan yang dipergunakan dapat dilihat pada tabel berikut:

Tabel 3

Distribusi Tanggapan Responden Mengenai Kesadaran

\begin{tabular}{|c|c|c|c|c|c|c|c|c|c|c|c|}
\hline \multirow{3}{*}{ ITEM } & \multicolumn{10}{|c|}{ SKOR } & \multirow{3}{*}{$\Sigma f$} \\
\hline & \multicolumn{2}{|c|}{1} & \multicolumn{2}{|c|}{2} & \multicolumn{2}{|c|}{3} & \multicolumn{2}{|c|}{4} & \multicolumn{2}{|c|}{5} & \\
\hline & $F$ & $\%$ & $F$ & $\%$ & $F$ & $\%$ & $F$ & $\%$ & $F$ & $\%$ & \\
\hline SDR_ 1 & $\mathrm{O}$ & $\mathrm{O}$ & 0 & 0 & 4 & 4 & 43 & 43 & 53 & 53 & 100 \\
\hline SDR_2 & 1 & 1 & O & $\mathrm{O}$ & 4 & 4 & 54 & 54 & 41 & 41 & 100 \\
\hline SDR_3 & $\mathrm{O}$ & $\mathrm{O}$ & $\mathrm{O}$ & $\mathrm{O}$ & 2 & 2 & 38 & 38 & 60 & 60 & 100 \\
\hline SDR_4 & $\mathrm{O}$ & $\mathrm{O}$ & O & $\mathrm{O}$ & 3 & 3 & 47 & 47 & 50 & 50 & 100 \\
\hline \multicolumn{12}{|c|}{ Maka: } \\
\hline$\Sigma f$ & 1 & 1 & O & O & 13 & 13 & 182 & 182 & 204 & 204 & 400 \\
\hline $\begin{array}{l}f x s \\
\text { (SkorAktual }\end{array}$ & 1 & 0,05 & $\mathrm{O}$ & O & 39 & 2.18 & 728 & 40.71 & 1020 & 57.05 & 1788 \\
\hline \multicolumn{12}{|l|}{ Diperoleh: } \\
\hline $\begin{array}{l}\text { Skor ideal = } \\
\left(\mathrm{X}_{1} \cdot \mathrm{X}_{2} \cdot \mathrm{X}_{3}\right)\end{array}$ & \multicolumn{3}{|c|}{ Skor maksimal $\left(\mathrm{X}_{1}\right)$} & \multicolumn{3}{|c|}{ Jlh pernyataan $\left(\mathrm{X}_{2}\right)$} & \multicolumn{3}{|c|}{$\begin{array}{l}\text { Jlh responden } \\
\qquad\left(\mathrm{X}_{3}\right)\end{array}$} & \multicolumn{2}{|c|}{ Skor Ideal } \\
\hline
\end{tabular}




\begin{tabular}{|c|c|c|c|c|}
\hline & 5 & 4 & 100 & 109 \\
\hline \multicolumn{4}{|l|}{ SkorAktual } & 1788 \\
\hline \multicolumn{4}{|c|}{ TkKecenderungan = perbandingan skor actual dengan skor ideal } & $16.40 \%$ \\
\hline
\end{tabular}

Berdasarkan perbandingan skor actual dan skor ideal di atas maka dapat disimpulkan bahwa tingkat kecenderungan variabel kesadaran berada pada rentang skor 13,60 - 16,81 yakni dikategorikan tinggi. Selanjutnya mengidentifikasi kecendrungan brand holistic terlebih dahulu dihitung nilai rata-rata ideal $=39$ dan Standar deviasi ideal $=8,67$. Berdasarkan hal tersebut diperoleh interval persentase skor untuk setiap kategori adalah sebagai berikut:

Tabel 4

Klasifikasi Persentase Interval Brand Holistic

\begin{tabular}{|c|c|c|}
\hline \multirow{2}{*}{ No } & \multicolumn{2}{|c|}{ Klasifikasi } \\
\cline { 2 - 3 } & Rentang Skor & Kategori \\
\hline 1 & 54,61 keatas & Sangat Tinggi \\
\hline 2 & $44,20-54,61$ & Tinggi \\
\hline 3 & $54,61-33,8$ & Sedang \\
\hline 4 & $23,39-54,61$ & Rendah \\
\hline 5 & $23,39-$ Kebawah & Sangat Rendah \\
\hline
\end{tabular}

Ada 13 pernyataan pada variabel brand holistic. Hasil tanggapan 100 orang responden terhadap pernyataan yang dipergunakan dapat dilihat pada tabel berikut:

Tabel 5

Distribusi Tanggapan Responden Mengenai Brand Holistic

\begin{tabular}{|c|c|c|c|c|c|c|c|c|c|c|c|}
\hline \multirow{3}{*}{ ITEM } & \multicolumn{10}{|c|}{ SKOR } & \multirow{3}{*}{$\Sigma f$} \\
\hline & \multicolumn{2}{|c|}{1} & \multicolumn{2}{|c|}{2} & \multicolumn{2}{|c|}{3} & \multicolumn{2}{|c|}{4} & \multicolumn{2}{|c|}{5} & \\
\hline & $F$ & $\%$ & $F$ & $\%$ & $F$ & $\%$ & $F$ & $\%$ & $F$ & $\%$ & \\
\hline HLSTK 1 & O & O & 0 & O & 6 & 6 & 41 & 41 & 53 & 53 & 100 \\
\hline HLSTK 2 & $\mathrm{O}$ & O & 0 & 0 & 5 & 5 & 47 & 47 & 48 & 48 & 100 \\
\hline HLSTK 3 & O & O & 1 & 1 & 3 & 3 & 44 & 44 & 52 & $5^{2}$ & 100 \\
\hline HLSTK 4 & O & O & 0 & O & 6 & 6 & 46 & 46 & 48 & 48 & 100 \\
\hline
\end{tabular}


223 |Kesadaran Konsumen Menggunakan Kosmetik Halal Serta Pengaruhnya Terhadap Brand Holistic

\begin{tabular}{|c|c|c|c|c|c|c|c|c|c|c|c|}
\hline HLSTK 5 & $\mathrm{o}$ & o & 1 & 1 & 3 & 3 & 43 & 43 & 53 & 53 & 100 \\
\hline HLSTK 6 & o & O & 0 & o & 3 & 3 & 35 & 35 & 60 & 60 & 100 \\
\hline HLSTK 7 & 0 & 0 & 2 & 2 & 6 & 6 & 40 & 40 & 52 & 52 & 100 \\
\hline HLSTK 8 & 0 & o & 0 & 0 & 5 & 5 & 42 & 42 & 53 & 53 & 100 \\
\hline HLSTK 9 & 0 & 0 & 0 & 0 & 3 & 3 & 39 & 39 & 58 & 58 & 100 \\
\hline HLSTK 10 & 0 & o & o & 0 & 4 & 4 & 39 & 39 & 57 & 57 & 100 \\
\hline HLSTK 11 & 0 & 0 & 1 & 1 & 5 & 5 & 39 & 39 & 55 & 55 & 100 \\
\hline HLSTK 12 & 0 & 0 & 0 & .0 & 5 & 5 & 42 & 42 & 53 & 53 & 100 \\
\hline HLSTK 13 & O & O & 0 & o & 5 & 5 & 164 & 164 & 270 & 270 & 100 \\
\hline \multicolumn{12}{|c|}{ Maka: } \\
\hline$\Sigma f$ & o & o & 5 & 5 & 59 & 59 & 539 & 539 & 696 & 696 & 1299 \\
\hline $\begin{array}{l}\Sigma f x s \\
\text { (SkorAktual }\end{array}$ & o & o & 10 & 0.17 & 177 & 3,03 & 2156 & $\begin{array}{c}37,0 \\
2\end{array}$ & 3480 & 59,76 & 5823 \\
\hline \multicolumn{12}{|l|}{ Diperoleh: } \\
\hline \multirow[t]{2}{*}{$\begin{array}{l}\text { Skor ideal }= \\
\left(\mathrm{X}_{1} \cdot \mathrm{X}_{2} \cdot \mathrm{X}_{3}\right)\end{array}$} & \multicolumn{3}{|c|}{ Skor maksimal $\left(\mathrm{X}_{1}\right)$} & \multicolumn{3}{|c|}{ Jlh pernyataan $\left(\mathrm{X}_{2}\right)$} & \multicolumn{3}{|c|}{$\begin{array}{l}\text { Jlh responden } \\
\left(\mathrm{X}_{3}\right)\end{array}$} & \multicolumn{2}{|c|}{ Skor Ideal } \\
\hline & \multicolumn{3}{|c|}{5} & \multicolumn{3}{|c|}{13} & \multicolumn{3}{|c|}{100} & \multicolumn{2}{|c|}{118} \\
\hline \multicolumn{10}{|l|}{ SkorAktual } & \multicolumn{2}{|c|}{5823} \\
\hline \multicolumn{10}{|c|}{ TkKecenderungan = perbandingan skor actual dengan skor ideal } & \multicolumn{2}{|c|}{$49,35 \%$} \\
\hline
\end{tabular}

Berdasarkan perbandingan skor actual dan skor ideal di atas maka dapat disimpulkan bahwa tingkat kecenderungan variabel brand holistic berada pada rentang skor 44,20-54,61, yaitu dikategorikan tinggi.

\section{HASIL DAN PEMBAHASAN}

Penelitian ini menggunakan pendekatan SEM yang berbasis variance (PLS) dengan alat SmartPLS 3.o. Adapun tahap-tahapnya adalah sebagai berikut:

\section{Pengujian Outer Model}

Pengujian ini dilakukan untuk mengukur kebaikan data yaitu validitas dan reliabilitas. Membangun validitas digunakan untuk menguji seberapa baik instrumen yang dibuat 
mengukur konstruksi tertentu. Sedangkan reliabilitas digunakan untuk menguji seberapa konsisten alat ukur telah mengukur konstruksinya

\section{Cross Loading}

Cross Loading merupakan korelasi konstruk dengan item pengukuran lebih besar dari pada ukuran konstruk lainnya, maka hal itu menunjukkan bahwa konstruk laten memprediksi ukuran pada blok mereka lebih baik dari pada ukuran blok lainnya (Fornell dan Larcker, dalam Ghozali, 2011). Hasil pengujian dari Cross Loading dapat dilihat pada tabel dibawah ini:

Tabel 6

\section{Cross Loading}

\begin{tabular}{|c|c|c|}
\hline Variabel & Kesadaan & Brand Holistic \\
\hline HLSTK_1 & 0.702 & $\mathbf{0 . 7 1 7}$ \\
\hline HLSTK_10 & 0.649 & 0.738 \\
\hline HLSTK_11 & 0.590 & 0.716 \\
\hline HLSTK_12 & 0.553 & 0.726 \\
\hline HLSTK_13 & 0.525 & 0.671 \\
\hline HLSTK_14 & 0.641 & $\mathbf{0 . 7 8 7}$ \\
\hline HLSTK_15 & 0.608 & 0.797 \\
\hline HLSTK_4 & 0.628 & 0.749 \\
\hline HLSTK_5 & 0.559 & 0.733 \\
\hline HLSTK_6 & 0.499 & 0.684 \\
\hline HLSTK_7 & 0.429 & 0.660 \\
\hline HLSTK_8 & 0.624 & 0.760 \\
\hline HLSTK_9 & 0.511 & 0.695 \\
\hline SDR_1 & 0.834 & 0.658 \\
\hline SDR_2 & 0.758 & 0.546 \\
\hline SDR_3 & 0.878 & 0.744 \\
\hline SDR_4 & 0.806 & 0.671 \\
\hline
\end{tabular}

Sumber: Data diolah (2018)

Berdasarkan Tabel 6, dapat disimpulkan bahwa korelasi nilai setiap konstruk lebih tinggi dari pada indikator lainnya.

\section{Convergent Validity}

Convergent validity dapa dilihat dari nilai Average Variance Extracted (AVE). Pada penelitian ini nilai AVE masing-masing konstruk berada diatas 0,5. Oleh karenanya tidak ada permasalahan konvergen validity pada model yang diuji. 


\section{5 |Kesadaran Konsumen Menggunakan Kosmetik Halal Serta Pengaruhnya}

Terhadap Brand Holistic

Tabel 7

Average Variance Extracted (AVE)

\begin{tabular}{ll}
\hline \multicolumn{1}{c}{ Konstruk } & AVE \\
\hline Kesadaran & 0,672 \\
Brand Holistic & 0,528 \\
\hline
\end{tabular}

Sumber: Data diolah (2018)

Dikarenakan tidak ada permasalahan convergen validity maka berikutnya yang di uji adalah permasalahan yang terkait dengan discriminant validity.

\section{Diskriminant Validity.}

Discriminant validity dapat diuji dengan membandingkan nilai cr akar kuadrat AVE dengan nilai korelasi antar konstuk.

Tabel 8

Nilai Akar Kuadrat AVE

\begin{tabular}{lcc}
\hline & Kesadaran & Brand Holistic \\
\hline Kesadaran & $\mathbf{0 , 8 2 0}$ & \\
Brand Holistic & 0,805 & $\mathbf{0 , 7 2 7}$ \\
\hline
\end{tabular}

Sumber: Data diolah (2018)

Adapun metode lain yang dapat digunakan untuk menguji diskriminant validity adalah dengan melihat dari table cross loading. Dari hasil cross loading tampak bahwa tidak terdapat permasalahan diskriminant validity.

\section{Uji Reliabilitas}

Untuk memastikan tidak ada masalah terkait pengukuran maka langkah terakhir dalam evaluasi outer model adalah menguji unidimensionalitas dari model. Uji ini dilakukan dengan menggunakan indicator composite reliability dan alpha cronbach. Untuk kedua indicator ini titik cut-off adalah 0,7 .

\section{Tabel 9}

Cronbach's Alpha dan Composite Reliability

\begin{tabular}{lcc}
\hline \multicolumn{1}{c}{ Variabel } & Cronbach's Alpha & Composite Reliability \\
\hline Brand Holistic & 0,837 & 0,891 \\
Kesadaran & 0,925 & 0,936 \\
\hline
\end{tabular}

Sumber: Data diolah (2018)

Tabel diatas menunjukkan bahwa konstuk memiliki nilai composite reliability o, 891 dan 0,936. Dapat disimpulkan penelitian ini mempunyi reliabilitas yang tinggi karena memiliki composite reliability >0,7. Uji reliabilitas ini juga diperkuat dengan cronbach alpha. 
Adapun nilai cronbach alpha konstruk 0,837 dan 0,925. Nilai cronbach alpha diharapkan >0.6 untuk konstruk.

\section{Pengujian Inner Model}

Evaluasi inner model dapat dilakukan dengan melihat dari R Square dan GoF. R square pada penelitian ini adalah o,648. Hal ini menunjukkkan bahwa besarnya keragaman model dalam penelitian ini sebesar $64,8 \%$. Sedangkan $35,2 \%$ dijelaskan oleh faktor lain. Skor R square 0,67 dikategorikan kuat, 0,33 dikategorikan moderat, dan 0,19 dikategorikan lemah (Chin, 1998). Selanjutnya mencari nilai Goodness of Fit (GoF) menurut Tenenhau (2004), nilai GoF 0,1 dikategorikan small, nilai GoF 0,25 dikategorikan medium dan nilai GoF 0,38 dikategorikan besar. Nilai GoF pada PLS-SEM dicari secara manual yaitu sebagai berikut:

$$
\begin{aligned}
& \text { Gof }=\sqrt{\overline{A V E \times \overline{R^{2}}}} \\
& \text { Gof }=1,243 \times 0,804 \\
& \text { Gof }=0,999
\end{aligned}
$$

Berdasarkan hasil perhitungan diatas nilai Goodness of Fit (GoF) sebesar 0,999. Hal ini menunjukkan bahwa nilai GoF index lebih besar dari o,38 termasuk dalam kategori besar. Dapat diambil kesimpulan bahwa model yang telah dibentuk dalam penelitian ini adalah baik.

\section{Uji Hipotesis Penelitian}

Menguji hipotesis dapat dilihat dari nilai t-statistik dan nilai probabilitas. Untuk pengujian hipotesis menggunakan nilai statistik maka untuk alpha $5 \%$ nilai t-statistik yang digunakan adalah 1,96. Sehingga kriteria penerimaan hipotesa adalah Ha diterima ketika tstatistik > 1,96. Untuk menolak/menerima Hipotesis menggunakan probabilitas maka Ha di terima jika nilai $\mathrm{p}<0,05$.

\section{Tabel 10}

\section{Path Coefficient}

\begin{tabular}{lcccccc}
\hline $\begin{array}{c}\text { Hipote } \\
\text { sis }\end{array}$ & Pengaruh & $\begin{array}{c}\text { Original } \\
\text { Sampel } \\
(\mathrm{o})\end{array}$ & $\begin{array}{c}\text { Mean } \\
(\mathrm{M})\end{array}$ & $\begin{array}{c}\text { Standard } \\
\text { Deviation } \\
\text { (STDEV) }\end{array}$ & $\begin{array}{c}\mathrm{T} \\
\text { Statistik }\end{array}$ & $\begin{array}{c}\mathrm{P} \\
\text { Values }\end{array}$ \\
\hline H1 & Kesadaran $\rightarrow$ Brand Holistic & 0,806 & 0,811 & 0,038 & 20,936 & 0,000 \\
\hline
\end{tabular}

Sumber: Data diolah (2018)

Berdasarkan tabel diatas dapat diinterpretasikan bahwa pengaruh kesadaran terhadap brand holistic menghasilkan nilai probability $0,000<0,05$ dan menghasilkan nilai t statistic 20,936 > t tabel 1,96, yaitu menunjukkan hipotesis terdukung. Artinya kesadaran memiliki 


\section{7 | Kesadaran Konsumen Menggunakan Kosmetik Halal Serta Pengaruhnya Terhadap Brand Holistic}

berpengaruh positif dan signifikan terhadap brand holistic. Model penelitian dapat dilihat pada Gambar 1 berikut ini:

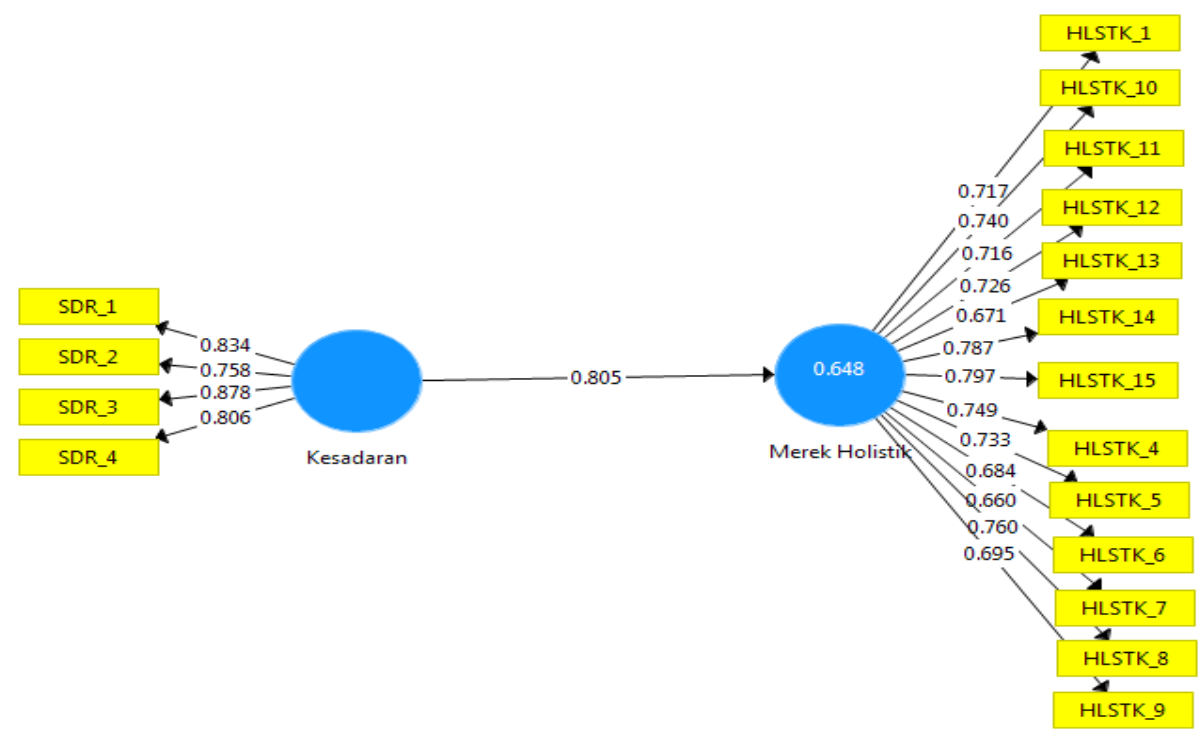

\section{Gambar 1. Hasil Analisis Jalur Model Penelitian}

Berdasarkan Gambar 1, dapat diinterpretasikan bahwa pengaruh kesadaran terhadap brand holistic sebanyak 80,5\%. Nilai R Square adalah koefisien determinasi pada konstruk endogen. Menurut Chin (1998), nilai R square sebesar 0.67 (kuat), 0.33 (moderat) dan 0.19 (lemah). Gambar 1, menunjukkan nilai konstruk endogen variabel brand holistic diatas 0.33 yaitu moderat. Maka dapat disimpulkan bahwa nilai R Square o,648 mengindikasikan bahwa 64,8\% variabel brand holistic dapat dijelaskan oleh kesadaran konsumen menggunakan kosmetik halal. Adapun tingkat kecendrungan kesadaran berada pada rentang skor 13,60 16,81 yakni dikategorikan tinggi. Begitu juga dengan tingkat kecendrungan variabel brand holistic berada pada rentang skor 44,20-54,61, yaitu dikategorikan tinggi. Pengaruh ini membuktikan bahwa wanita dewasa memiliki kesadaran yang sangat tinggi terhadap kosmetik halal dan brand holistic.

Temuan ini sejalan dengan pendapat Keller (2001) bahwa membangun identitas merek yang tepat dengan mempelajari secara luas dan mendalam kesadaran konsumen terhadap merek. Adapun indikator yang menunjukkan kesadaran tersebut adalah (1) mereka mengetahui kosmetik halal merupakan produk kecantikan yang sesuai dengan keyakinan agama mereka; (2) mereka menghindari produk kosmetik yang tidak jelas kehalalannya; (3) mereka menggunakan kosmetik halal dan baik serta ;4) mereka mencari informasi tentang kejelasan kosmetik yang mereka pakai. Temuan ini sejalan dengan pendapat Pawlik (1998), Anderson (1994), dan Zeman (2001) bahwa kesadaran seseorang terhadap kosmetik karena pengetahuannya, keyakinannya, situasi yang pernah dialaminya, dan melalui informasi yang 
ia dapatkan mengenai kosmetik. Kotler dan Keller (2009) menyatakan, konsumen akan membentuk persepsi yang lebih baik terhadap sebuah produk dengan merek yang telah dianggap positif. Dengan kata lain persepsi yang baik akan timbul jika konsumen memiliki keyakinan, pengetahuan, pengalaman dan mendapatkan informasi tentang kosmetik yang bernilai positif itu.

Adapun unsur-unsur brand holistic pada kosmetik yang diujikan peneliti adalah: (1) merek kosmetik yang dapat memberikan keindahan dan kemewahan kulit yang sehat, namun tetap setia pada prinsip kepercayaan (religious); (2) menggunakan kosmetik yang bebas dari lemak hewani; (3) menggunakan kosmetik dari bahan-bahan alami agar dapat mengurangi kehawatiran bagi konsumen; (4) memakai bahan kosmetik yang tidak dihasilkan secara tidak manusiawi yaitu menolak melakukan uji coba terhadap hewan (kekejaman bebas) untuk dijadikan bahan kosmetik; (5) peduli lingkungan dan menolak eksploitasi besar-besaran sampai mengakibatkan kepunahan yang digunakan untuk bahan kosmetik; (6) kosmetik harus memiliki label/logo yang menunjukkan indikisi holistic seperti label halal, jaminan bpom, dan higienis agar konsumen terlindungi; (7) proses pembuatan produk kecantikan yang bersih, termasuk cairan yang digunakan untuk membersihkan peralatan pembuatan kosmetik; (8) bahan alami, tanpa bahan kimia berbahaya, dan pembuatannya higienis selain menyehatkan dan tidak menyebabkan ketergantungan serta dapat memberikan ketenangan akal pikiran, jiwa dan raga; (9) kosmetik yang dapat dipakai oleh semua orang, atau dapat digunakan oleh berbagai latar belakang manusia, sehingga terwujud aplikasi holistik ditengah masyarakat dunia.

Respon konsumen terhadap pernyataan bahwa mereka setuju merek kosmetik yang dapat memberikan keindahan dan kemewahan kulit yang sehat, namun tetap setia pada prinsip kepercayaan (religious) Temuan tersebut sejalan dengan pendapat Schiffman \& Kanuk (1997) yaitu bahwa anggota dari berbagai keputusan pembelian kelompok agama dipengaruhi oleh agama dan kepercayaan mereka. Temuan penelitian ini juga sejalan dengan penelitian sebelumnya yaitu penelitian Abdul Raufu (2014) bahwa meningkatnya permintaan akan konsumsi halal dibantu oleh sejumlah faktor potensial atau sumber yang diidentifikasi salah satunya adalah keyakinan agama. Begitu juga pada penelitian Azmawani (2013) yaitu terdapat hubungan yang positif antara keyakinan agama dengan sikap konsumen terhadap kosmetik halal.

Pernyataan konsumen selanjutnya bahwa mereka setuju menggunakan kosmetik dari bahan-bahan alami agar dapat mengurangi kehawatiran bagi mereka. Pernyataan ini sejalan dengan temuan Azreen (2014) menunjukkan bahwa kandungan atau bahan dari produk kosmetik merupakan faktor yang paling penting dapat mempengaruhi mereka untuk mengkonsumsi produk kosmetik. hal ini juga berkaitan dengan pernyataan konsumen 


\section{9 |Kesadaran Konsumen Menggunakan Kosmetik Halal Serta Pengaruhnya Terhadap Brand Holistic}

bahwasanya mereka setuju kosmetik itu terbuat dari bahan alami, tanpa bahan kimia berbahaya, dan pembuatannya higienis selain menyehatkan dan tidak menyebabkan ketergantungan serta dapat memberikan ketenangan akal pikiran, jiwa dan raga. Temuan ini sesuai dengan penelitian Isabelle (2015) yaitu mereka mengidentifikasi salah satu atribut brand holistic adalah kehebatan dan kesehatan.

Selanjutnya pernyataan konsumen yaitu mereka setuju kosmetik harus memiliki label/logo yang menunjukkan indikisi holistic seperti label halal, jaminan BPOM, dan higienis agar konsumen terlindungi. Wilson (2017) menegaskan bahwa kemungkinan besar perusahaan yang sukses adalah mereka yang tidak hanya melibatkan manajer merek, tetapi individu dengan keahlian penciptaan, pengembangan dan pengelolaan gambar dan simbol.

Pernyataan lainnya bahwa konsumen setuju jika perusahaan memaparkan mereknya sesuai dengan kenyataan (jujur). Hal ini sejalan dengan pendapat Keller (2001) yaitu merek memaparkan makna merek yang sesuai, kuat, menguntungkan, dan kumpulan merek yang unik serta mudah diakses sehingga dapat memberikan kesadaran konsumen terhadap merek. Menurut Anderson (1994) konsumen harus mengandalkan penjual atau pihak luar seperti pengamat, dan menaruh kepercayaan mereka pada sumber informasi dan informasi yang diterima.

Hasil identifikasi ini sejalan dengan penafsiran Ar-Razi (2003) bahwa Allah sangat mencintai orang yang suci dari dosa, berbagai bentuk maksiat dan berbagai macam kotoran. Sebagai seorang muslim harus menjauhi najis ruhaniyah (berbagai macam kemaksiatan). Sedangkan yang ruhaniyah saja merupakan najis apalagi yang zhohiriyah (sudah jelas unsur yang diharamkan). Maka kosmetik yang dipakai semestinya suci atau halal. Karena dari kata halal memberikan efek positif yaitu kesehatan, baik, bersih, indah, suci, dan tidak bertentangan dengan kepercayaan orang lain.

Semua unsur brand holistic pada kosmetik saling pengaruh mempengaruhi agar konsumen memiliki kesadaran. Hasil penelitian ini dapat dijelaskan bahwa seseorang membutuhkan kosmetik, tetapi ia ingin kosmetik yang tidak merusak kepercayaanya. Konsumen membeli kosmetik karena ingin cantik dan sehat maka ia akan melihat manfaatnya. Pengalaman seseorang memakai kosmetik akan terjadi dua kemungkinan yaitu jika kosmetik itu berdampak positip baginya ia akan membelinya lagi dan jika kosmetik itu berdampak negatif misalkan merusak kulit maka ia tidak membelinya lagi. Maka sangat penting memproduksi kosmetik yang berkualitas agar pelanggan tetap membelinya. Kemudahan mengakses segala sesuatu merupakan tantangan. Seseorang sadar terhadap kosmetik karena mendapatkan informasi dari berbagai sumber. Maka penting menginformasikan tentang kosmetik yang diproduksi secara baik dan sesuai kenyataanya. Seseorang yang peduli lingkungan tidak setuju jika bahan-bahan kosmetik hasil dari eksploitasi yang mengakibatkan kepunahan. Konsumen akan menaruh kepercayaannya pada lembaga sertifikasi label/logo, 
agar mereka terlindungi dari bahan-bahan yang berbahaya. Karena itu konsumen lebih memilih produk kosmetik yang memiliki label/logo.

\section{KESIMPULAN}

Terdapat beberapa indikator yang mempengaruhi kesadaran konsumen menggunakan kosmetik halal yaitu pengetahuan, keyakinan, situasi yang pernah dialami, dan melalui informasi yang ia dapatkan mengenai kosmetik halal. Kesadaran konsumen menggunakan kosmetik halal berpengaruh positif dan signifikan terhadap brand holistic. Adapun unsur-unsur brand holistic pada kosmetik yaitu (1) Tidak bertentangan dengan prinsip kepercayaan; (2) indah dan sehat; (3) menggunakan bahan-bahan alami; (4) peduli lingkungan dan menolak eksploitasi; (5) bebas dari lemak hewani; (6) proses pembuatan yang bersih; (7) pengawasan yang ketat terhadap sertifikasi label/logo; (8) tidak menyebabkan ketergantungan; (9) memberikan ketenangan akal pikiran, jiwa dan raga; (10) pemaparan yang sesuai dengan kenyataan; (11) dan dapat digunakan berbagai latar belakang manusia. Semua unsur ini mempengaruhi kesadaran konsumen menggunakan kosmetik. Maka disarankan bagi perusahaan agar dapat memperkokoh brandnya, sangat penting mengintegrasikan semua unsur pada merek.

\section{DAFTAR PUSTAKA}

Aaker, Jenifer L. (1997). Dimensions of Brand Personality. Journal of Marketing Research. 347-5. https://www.gsb.stanford.edu.

Abd Rahman, Azmawani dan Ebrahim Asrarhaghighi Suhaimi Ab Rahman. (2013).Consumers and Halal cosmetic products: knowledge, religiosity, attitude and intention. Journal of Islamic Marketing, Vol. 6 Iss 1 pp. -. Emerald Group Publishing Limited

Al-Asyqar, Muhammad Sulaiman. (2013). Zubdat At-Tafsir. Jordan:Dar al-Nafaes

Al-Qardhawi, Yusuf. (1985). al-Halal Wa Haram fi Islam. Cet- I, Beiruth: Darul Ma'rifah.

Al-Qardhawi, Yusuf. (1997). Norma dan Etika Ekonomi Islam. Terjemahan Zainul Arifin. Jakarta: Gema Insani Press.

Ambalia, Abdul Raufu dan Bakara, Ahmad Naqiyuddin. ( 2014 ) . People's Awareness on Halal Foods and Products: Potential Issues for Policy-Makers, The Jurnal Of international Procedia - Social and Behavioral Sciences $1213-25$.

Anderson, W. E., Fornell, C. \& Rust, T. R. (1994). Customer satisfaction, productivity and profitability: Differences between goods and services. Marketing Science, 16(2), 129145. Dalam jurnal Abdul Raufu Ambalia dan Ahmad Naqiyuddin Bakara, People's Awareness, ...h.10. 
Aoun, Isabelle \& Laurent Tournois. (2015). Building holistic brands: an exploratory study of Halal cosmetics, (Emerald Group Publishing Limited) Journal of Islamic Marketing, Vol. 6 h.7

Ar-razi, Fakhruddin. (2003). Tafsir al-Kabir Mafaatih Al-Ghaib. Jilid ke-3. Mesir, Cairo: Maktabah At-Taufiqiyah.

Batsos, Wilson \& Sidney J. Levy. 2017. “Sejaran Konsep Branding: Praktik dan Teori”, dalam, www.emeraldinsight.com/1755-750X.htm, Departemen Pemasaran, Universitas Arizona, Tucson, Arizona, AS, h.362

Chin, W.W. (1998). “The partial least squares approach to structural equation modeling”. In G.A.Marcoulides (Ed.), Modern Methods for Business Research, N.J., Lawrence Erlbaum Associates: Mahwah, 295-358

Fatwa MUI No. 26 Tahun 2013 Tentang Standar Kehalalan Produk Kosmetika dan Penggunaannya

Fornell, C. dan Larcker, D. F. (1981). Evaluating Structural Equation Models with Unobservable Variables and Measurement Error. Journal of Marketing Research. Dalam Ghozali. I. (2011). Structural Equation Modeling Metode Alternatif dengan Partial Least Square. Semarang: Badan Penerbit Undip.

Jihan, A zreen, Che Mohd Hashim \& Rosidah Musa. ( 2014 ). Factors Influencing Attitude Towards Halal Cosmetic Among Young Adult Urban Muslim Women: A Focus Group Analysis. Procedia - Social and Behavioral Sciences 130129 - 134. (www.sciencedirect.com)

Keller, Kevin Lane. (2001). Building Customer-Based Brand Equity: A Blue Print For Creating Strong Brands. Cambridge : Marketing Science Institute. www.msi.org

Kementerian Perdagangan Republik Indonesia, "Hidup Sehat dengan Produk Halal”, dalam Warta Ekspor (Ditjen PEN/WRT/56/VII/2015 Edisi juli) .5.

Kolter, Philip dan Kevin Lane Keller. (2009). Alih Bahasa: Benyamin Molan. Manajemen Pemasaran. Jilid 1. Edisi ke-12. Cet ke-4. Jakarta : PT. Indeks.

Kuncoro, Mudrajad.(2003). Metode Riset Untuk Bisnis dan Ekonomi. Jakarta:Penerbit : Erlangga.

Schiffman L.G. \& Kanuk, L.L. (1997). Consumer behaviour N.J. Prentice-Hall. Dalam Ambalia, Abdul Raufu dan Bakara, Ahmad Naqiyuddin. People’s Awareness,...p.9 